\title{
Effect of dementia on the incidence, short- term outcomes, and resource utilization of invasive mechanical ventilation in the elderly: a nationwide population-based study
}

${\text { Carmen Bouza }{ }^{1 *} \text { (D) Gonzalo Martínez-Alés }}^{2,3}$ and Teresa López-Cuadrado ${ }^{4}$

\begin{abstract}
Background: Though the prevalence of dementia among hospitalized patients is increasing, there is limited population data in Europe about the use of life-support measures such as invasive mechanical ventilation in these patients. Our objective is to assess whether dementia influences the incidence, outcomes, and hospital resource use in elderly patients undergoing mechanical ventilation.
\end{abstract}

Methods: Using ICD-9-CM codes, all hospitalizations involving invasive mechanical ventilation in adults aged $\geq 65$ years were identified in the Spanish national hospital discharge database covering the period 2000-2013. The cases identified were stratified into two cohorts (patients with or without dementia) in which main outcome measures were compared. The impact of dementia on in-hospital mortality and hospital resource use were assessed through multivariable models. Trends were assessed through joinpoint regression analysis and results expressed as average annual percentage change.

Results: Of the 259,623 cases identified, 5770 (2.2\%) had been assigned codes for dementia. Cases with dementia were older, had a lower Charlson comorbidity score, and less frequently received prolonged mechanical ventilation or were assigned a surgical DRG. Circulatory disease was the most common main diagnosis in both cohorts. No significant impact of dementia was observed on in-hospital mortality (adjusted OR 1.04, [95\% Cl] 0.98, 1.09). In the cohort with dementia, the incidence of mechanical ventilation underwent an average annual increase over time of $5.39 \%(95 \% \mathrm{Cl} 4.0,6.7)$ while this rate was $1.62 \%(95 \% \mathrm{Cl} 0.9,2.4)$ in cases without dementia. However, unlike this cohort, mortality in cases with dementia did not significantly decline over time. Geometric mean hospital cost and stay were lower among cases with than without dementia (-14\% [95\% Cl -12\%, -15\%] and $-12 \%[95 \% \mathrm{Cl},-9 \%,-14 \%]$, respectively), and these differences increased over time.

Conclusion: This nationwide population-based study suggests no impact of dementia on in-hospital mortality in elderly patients undergoing invasive mechanical ventilation. However, dementia is significantly associated with shorter stay and hospital costs. Our data also identifies a recent marked increase in the use of this lifesupport measure in elderly patients with dementia and that this increase is much greater than that observed in elderly individuals without dementia.

Keywords: Dementia, Elderly, Mechanical ventilation, Incidence, Outcomes, Trends

\footnotetext{
* Correspondence: cbouza@isciii.es

${ }^{1}$ Health Technology Assessment Agency, Carlos III Health Institute, c/

Monforte de Lemos 5, Pab 4, 28029 Madrid, Spain

Full list of author information is available at the end of the article
}

(c) The Author(s). 2019 Open Access This article is distributed under the terms of the Creative Commons Attribution 4.0 International License (http://creativecommons.org/licenses/by/4.0/), which permits unrestricted use, distribution, and reproduction in any medium, provided you give appropriate credit to the original author(s) and the source, provide a link to the Creative Commons license, and indicate if changes were made. The Creative Commons Public Domain Dedication waiver (http://creativecommons.org/publicdomain/zero/1.0/) applies to the data made available in this article, unless otherwise stated. 


\section{Background}

Dementia is one of the greatest health problems among persons aged 65 years or older worldwide. Because of population aging and a lack of effective prevention and treatment measures, it has been estimated that in the foreseeable future, the number of affected persons will double $[1,2]$.

The prevalence of dementia among hospitalized patients is also increasing [3-5], but the balance of potential benefits and harm of intensive care interventions in this population is unclear. In fact, the last few years have witnessed intense debate regarding life-support intensive treatment in patients with dementia such as invasive mechanical ventilation (MV) [6-9]. MV is a key component of the management of critically ill patients with acute or chronic respiratory failure. However, it is associated with a high mortality [10], with short- and long-term complications $[11,12]$, and requires a complex care level with a substantial impact on hospital resources [13].

Despite these considerations, few studies have examined trends in its use in patients with dementia. The scarce data available come from the USA and Canada where several authors have reported a sustained increased use of MV in patients with dementia in the past few decades $[14,15]$ with clinical outcomes comparable to those observed in patients without dementia [16].

Spain is a rapidly aging country and dementia prevalences are among the highest in the world (https://www. alzheimer-europe.org/Policy-in-Practice2/Country-comparisons/2013-The-prevalence-of-dementia-in-Europe/ Spain). This determines the need to characterize the use of MV and its trends in these patients since the use of effective and safe therapeutic technologies and the appropriate use of healthcare resources are priority objectives in a quality health system. Accordingly, this study sought to examine the characteristics of $\mathrm{MV}$ and its recent trends in incidence, associated mortality, and hospital resource use in patients $\geq 65$ years with and without dementia based on data from Spain's national hospital discharge database.

\section{Methods}

\section{Study design and data sources}

We performed a retrospective population-based study using the Spanish Health Ministry's National Minimum Basic Data Set (MBDS). This official database gathers information derived from discharge reports from all acute-care hospitals in Spain. For each hospitalization, demographic and clinical information is provided including a main diagnosis, 13 secondary diagnoses, and up to 20 procedures coded at each center before patient discharge according to International Classification of Diseases, Ninth Edition, Clinical Modification (ICD-9-CM) codes as well as corresponding diagnosis-related group
(DRG) codes. This information, whose registration is mandatory by law in the National Health System, is considered to be representative of the national population as the database covers over $90 \%$ of all annual hospital admissions produced in our country [17].

To calculate incidence rates, we used population data provided by the Spanish Statistics Institute [18]. Hospital admissions data were provided by the Ministry of Health, Resources and Welfare [17]. All data used are anonymous so, according to Spanish law, the need was waived for informed consent [19].

\section{Study population: case definitions and identification}

Hospitalizations involving subjects $\geq 65$ years who received MV from January 1, 2000, to December 31, 2013, were identified using the ICD-9-CM codes: 96.70 (continuous invasive MV of unspecified duration), 96.71 (continuous invasive $\mathrm{MV}<96$ consecutive hours) and 96.72 (continuous invasive $\mathrm{MV} \geq 96$ consecutive hours). These codes are considered specific, stable, and valid [20].

According to ICD-9-CM coding norms, one of these codes is assigned to hospitalized patients who require MV except if used during a routine surgical procedure. Postsurgery MV is coded if lasting more than 2 days or if the clinician reports its duration was longer than planned. MV duration was measured from the moment of endotracheal intubation [17].

Dementia is a clinical syndrome characterized by a global, progressive cognitive impairment that generates functional decline and disability [21]. A variety of braindamaging conditions, such as degenerative, vascular, metabolic, or toxic brain disease, can lead to dementia, and although the most frequent cause of dementia from middle age to elderly is Alzheimer's disease, most patients suffer from a mixture of different pathologies [21]. We defined dementia as the presence in any of the diagnoses entered in the database of the ICD-9-CM codes: 290.0-290.9 (dementias), 291.1 (alcohol-induced persisting amnestic disorder), 291.2 (alcohol-induced persisting dementia), 292.82 (drug-induced persisting dementia), 292.83 (drug-induced persisting amnestic disorder), 294.0 (amnestic disorder in conditions classified elsewhere), 294.1 (dementia in conditions classified elsewhere), 294.2 (dementia, unspecified), 294.8 (other persistent mental disorders due to conditions classified elsewhere), 294.9 (unspecified persistent mental disorders due to conditions classified elsewhere), 331.0 (Alzheimer's disease), 331.1 (frontotemporal dementia), 331.2 (senile degeneration of the brain), 331.7 (cerebral degeneration in diseases classified elsewhere), 331.82 (dementia with Lewy bodies), and 331.9 (cerebral degeneration, unspecified). Similar broad definitions of dementia have been used by others [14] to improve case detection. 
To assess the comorbidity burden, we used the Charlson index score validated by Deyo [22] and improved for ICD-9-CM [23] according to secondary diagnoses. For the purposes of this study, dementia itself was excluded in the Charlson Index [24].

For every case, the main diagnostic group was assessed according to the ICD-9-CM chapters: infectious disease (001-139), neoplasms (140-239), endocrine diseases (240-279), hematological diseases (280-289), neurological diseases (320-389), diseases of the circulatory system (390-459), respiratory diseases (460-519), diseases of the digestive system (520-579), diseases of the genitourinary tract (580-629), diseases of the skin and subcutaneous tissue (680-709), diseases of the musculoskeletal system and connective tissue (713-739), and injury-poisoning (800-999).

\section{Data analysis}

We conducted a descriptive and comparative analysis of cases with and without dementia, including demographic and clinical information, comorbidity burden, and hospital mortality, stay, and costs. Charlson comorbidity scores are provided as a continuous variable and as categorical with 4 groups $(0,1-2,3-4,>4)$ of increasing severity and impact on outcomes [25]. Categorical variables are expressed as absolute frequencies and percentages while continuous variables are given as geometric means and geometric standard deviation (SD), as geometric means are less influenced by extreme values than arithmetic ones. To test differences in categorical variables, we used Pearson's chi-square test.

In-hospital mortality was estimated as the number of deaths relative to the number of cases and expressed as a percentage, or case fatality rate (CFR). To examine the effect of dementia on mortality, stay, and costs, we conducted regression models (logistic regressions for mortality and linear regressions of log-transformed stay and costs) and adjusted them in two multivariable models. Model 1 was adjusted for baseline characteristics (age, sex, Charlson index) whereas model 2 also included the principal diagnosis at admission and MV duration. Results are expressed as odds ratios (OR) with 95\% confidence intervals (for mortality) and geometric means ratio with $95 \%$ confidence intervals (for stays and costs).

We examined temporal trends in MV incidence rate (per 100,000 people and per 10,000 hospital discharges), proportion of MV cases with dementia, prolonged MV (defined as a duration of $\geq 96$ consecutive hours according to the ICD-9-CM codification system), and CFR. To this end, we used joinpoint regression models-generalized linear models that assume a Poisson distribution [26]. In these models, any apparent trend can be statistically assessed through a Monte Carlo permutation method
[27]. Trends are presented as the average annual percentage change (AAPC), a summary measure of the overall trend over the study period. To compare the AAPC of both study groups, we examined whether their regression mean functions were parallel, allowing for different intercepts, using the Pairwise comparison parallel test. In addition, we analyzed trends in length of stay and costs using Cuzick's $p$ trend test.

All tests were performed using the packages STATA 15 (StataCorp. LP, College Station, TX, USA) and Joinpoint Regression 4.7.0.0. Significance was set at $p<0.05$.

\section{Results}

Out of the 19,979,322 hospitalizations in persons aged $\geq$ 65 years produced over the 14-year study period, 259, 623 cases underwent MV. Of these, 5770 (2.2\%) were cases with dementia.

As may be seen in Table 1, in the dementia cohort, the proportions of women and older age strata were higher than in the cohort without dementia. The Charlson score, however, was lower indicating a lower comorbidity burden among those with dementia. Among the main comorbidities, we should highlight a greater presence of cerebrovascular disease in the group of patients with dementia. Circulatory disease was the most common main diagnosis in both cohorts and was followed with disparate frequency in each one by respiratory disease, injury-poisoning, and digestive disorders. Conversely, cancer was much less frequent in the cases with dementia. Registries including dementia corresponded more to smaller hospitals, and patients less frequently received prolonged MV or were assigned a surgical DRG than in the nondementia group. The cohort with dementia showed a slightly, yet significantly, higher in-hospital mortality, and this difference was attributable only to cases subjected to short-duration MV (Additional file 1: Table S1). However, as may be observed in Table 2, according to the logistic regression analysis adjusted for age, sex, comorbidity burden, main diagnosis, and MV duration, dementia had no significant impact on in-hospital mortality.

Among the survivors, $78 \%$ of cases with dementia and $81 \%$ of those without dementia were discharged home while $16.3 \%$ and $15.1 \%$ respectively were discharged to long-term care centers.

Both geometric mean stay and hospital costs for the dementia group were significantly lower than for the non-dementia group (Table 2). Further, multivariate analysis of the impacts of dementia on hospital resource use indicated that dementia was associated significantly with a shorter adjusted mean hospital stay and lower mean hospital costs per case. 
Table 1 General characteristics of adults $\geq 65$ years receiving invasive mechanical ventilation

\begin{tabular}{|c|c|c|c|c|}
\hline & With dementia & Without dementia & OR $(95 \% \mathrm{Cl})$ & $p$ value \\
\hline & $5770(2.2)$ & $253,853(97.8)$ & & \\
\hline Gender women & $2702(46.8)$ & $96,946(38.2)$ & $1.43(1.35,1.50)$ & $<0.001$ \\
\hline \multicolumn{5}{|l|}{ Age } \\
\hline $65-74$ years & $1787(31.0)$ & $131,717(51.9)$ & Ref. & \\
\hline $75-84$ years & $3166(54.9)$ & $108,990(42.9)$ & $2.14(2.02,2.27)$ & $<0.001$ \\
\hline$>84$ years & $817(14.1)$ & $13,146(5.2)$ & $4.58(4.21,4.99)$ & $<0.001$ \\
\hline \multicolumn{5}{|l|}{ Charlson Index score } \\
\hline 0 points & $1891(32.8)$ & $77,478(30.5)$ & Ref. & \\
\hline $1-2$ points & $2932(50.8)$ & $124,467(49.0)$ & $0.97(.91,1.02)$ & 0.235 \\
\hline 3-4 points & $734(12.7)$ & $37,678(14.8)$ & $0.80(0.73,0.87)$ & $<0.001$ \\
\hline$>4$ points & $213(3.7)$ & $14,230(5.6)$ & $0.61(0.53,0.71)$ & $<0.001$ \\
\hline \multicolumn{5}{|l|}{ Main Charlson comorbidities } \\
\hline Diabetes & $1476(25.6)$ & $59,879(23.6)$ & $1.10(1.03,1.14)$ & $<0.001$ \\
\hline Cerebrovascular disease & $1048(18.2)$ & $18,972(7.5)$ & $2.75(2.57,2.94)$ & $<0.001$ \\
\hline COPD & $1005(17.4)$ & $54,918(21.6)$ & $0.76(0.71,0.82)$ & $<0.001$ \\
\hline Heart failure & $836(14.5)$ & $47,921(18.9)$ & $0.73(0.68,0.78)$ & $<0.001$ \\
\hline \multicolumn{5}{|l|}{ ICD-9-CM main diagnosis } \\
\hline Circulatory & $1751(30.3)$ & $98,683(38.9)$ & $0.69(0.65,0.73)$ & $<0.001$ \\
\hline Respiratory & $984(17.0)$ & $39,379(15.5)$ & $1.12(1.04,1.20)$ & 0.001 \\
\hline Injury-poisoning & $910(15.8)$ & $27,338(10.8)$ & $1.55(1.44,1.67)$ & $<0.001$ \\
\hline Digestive & $805(14.0)$ & $29,621(11.7)$ & $1.23(1.14,1.32)$ & $<0.001$ \\
\hline Cancer & $364(6.3)$ & $29,229(11.5)$ & $0.52(0.47,0.58)$ & $<0.001$ \\
\hline \multicolumn{5}{|l|}{ No. of hospital beds } \\
\hline$<200$ & $691(12.0)$ & $26,929(10.6)$ & Ref & \\
\hline $200-500$ & $1927(33.4)$ & $71,698(28.2)$ & $1.05(0.96,1.14)$ & 0.302 \\
\hline $501-1000$ & $1774(30.8)$ & $87,898(34.6)$ & $0.79(0.72,0.86)$ & $<0.001$ \\
\hline$>1000$ & $1378(23.9)$ & $67,327(26.5)$ & $0.80(0.73,0.87)$ & $<0.001$ \\
\hline DRG surgical & $2455(42.6)$ & $145,001(57.2)$ & $0.56(0.53,0.59)$ & $<0.001$ \\
\hline Mechanical ventilation $\geq 96 \mathrm{~h}$ & $1729(30.0)$ & $85,162(33.6)$ & $0.85(0.80,0.90)$ & $<0.001$ \\
\hline In-hospital mortality (CFR) & $2992(51.9)$ & $123,445(48.6)$ & $1.14(1.08,1.20)$ & $<0.001$ \\
\hline
\end{tabular}

Data presented as number of cases (\%)

$O R$ odds ratio, $\mathrm{Cl}$ confidence interval, COPD chronic obstructive pulmonary disease, $D R G$ diagnosis-related group, CRF case fatality rate

Table 2 Impact of dementia on in-hospital mortality and hospital resource use

\begin{tabular}{llllll}
\hline & With dementia & Without dementia & Crude & Model 1 & Model 2 \\
CFR & $(\%)$ & $(\%)$ & OR $(95 \% \mathrm{Cl})$ & Adjusted OR $(95 \% \mathrm{Cl})$ & \\
& 51.9 & 48.6 & $1.14(1.08,1.20)$ & $1.05(0.99,1.1)$ & $1.04(0.98,1.09)$ \\
Hospital stay, days & $11.16(3.20)$ & $14.01(3.19)$ & $0.80(0.77,0.82)$ & $0.85(0.82,0.87)$ & $0.88(0.86,0.91)$ \\
Costs, $€$ & $10,423(2.34)$ & $12,855(2.40)$ & $0.81(0.79,0.83)$ & $0.83(0.81,0.85)$ & $0.86(0.85,0.88)$ \\
\hline
\end{tabular}

Model 1: adjusted for sex, age, Charlson index

Model 2: adjusted for sex, age, Charlson index, main diagnosis, and length of MV

CFR case fatality rate, SD standard deviation 


\section{Temporal trends}

Rates of MV use referred to hospital discharges and the general population underwent a significantly greater increase among the subjects with dementia compared to those without (Table 3). In patients with dementia, the rate of MV use per 10,000 hospital discharges went up from 1.76 in 2000 to 3.57 in 2013, with an AAPC of $4.7 \%$. Meanwhile, in patients without dementia, the rate of MV use per 10,000 hospital discharges went up from 114.5 in 2000 to 131.3 in 2013 with an AAPC of $0.91 \%$. According to the comparability test, trends of MV in dementia and non-dementia cases were different ( $p$ value for test for parallelism $=0.005)$. The population incidence of MV in people with dementia rose from 3.1 to 6.9 per 100,000 inhabitants $\geq 65$ years, yielding an AAPC of $5.39 \%$, while in the non-dementia group it increased from 203.6 to 253.3, for an AAPC of 1.62\% (Fig. 1). According to the comparability test, population incidence trends in dementia and non-dementia were also different ( $p$ value for test for parallelism $=0.03$ ).

Table 3 also provides temporal trends in the use of $\mathrm{VM} \geq 96 \mathrm{~h}$ and in-hospital mortality (CFR), indicating that subjects with dementia underwent no significant changes over the study period, while in the nondementia cohort the use of prolonged MV increased and mortality decreased. As shown in Fig. 2, cases with dementia have not followed the descending trend shown by the cases without dementia; rather, mortality has fluctuated over time.

Figure 3 illustrates that geometric mean hospital stay in the cohort with dementia has steadily declined over time, while it has been relatively stable in the cohort without dementia. Geometric mean hospital costs per case have risen markedly over the study period. This increase has been nevertheless lower among cases with dementia, and inter-cohort differences have persisted (Fig. 3).

\section{Discussion}

The findings of this population-based study indicate that the use of MV in elderly persons diagnosed with dementia has shown a marked increase in Spain between the years 2000 and 2013. Further, this increase has been higher than that observed in their dementia-free counterparts. They also reveal that while no impacts of dementia on hospital mortality were detected, the declining trend in mortality produced in patients without dementia was not observed. In addition, compared with subjects free of dementia, these individuals incur lower hospital costs and length of stay.

As far as we know, this is the first study to characterize the pattern of MV use in adults $\geq 65$ years with and without dementia in a European country. The demographic and clinical characteristics of our cases are similar to those described in the USA and Canada [14, 15], although dementia appears as notably less frequent among those receiving $\mathrm{MV}$ in our setting. Only $2.2 \%$ of hospitalized adults aged $\geq 65$ years undergoing MV had been assigned a code for dementia, contrasting with the $15 \%$ and the $8.6 \%$ rates described in those studies. Our results show in the cohort of patients with dementia a marked increase in the incidence of MV with an average annual increase of $5.39 \%$, which is much higher than the $1.62 \%$ observed in the cohort without dementia. Notwithstanding, the increase detected was markedly lower than that reported by Lagu (11.4\%) and by Borjaille (7.8\%) in adults $\geq 65$ years with dementia [14, 15]. In part, these differences could be explained by the very different healthcare systems and the organizational models used for the care of critically ill patients between countries [28]. We should not forget that in a healthcare setting, offer is an important regulator of demand. Effectively in the USA, the increased use of MV in patients with advanced dementia has been linked to a greater availability of beds in intensive care units [29]. In Spain, with its universal, equalaccess healthcare system, it is estimated that in 2010 there were some 9.6 ICU beds per 100,000 inhabitants $[30,31]$ while in the USA this was around four times this figure in 2009 [32]. But, in spite of these differences, our data are in line with those reported in North America and contrast with prior studies indicating that acute care patients with dementia are treated substantially less aggressively than patients without dementia [8].

Table 3 Trend analysis

\begin{tabular}{|c|c|c|c|c|c|c|c|}
\hline & \multicolumn{3}{|c|}{ MV in cases with dementia } & \multicolumn{3}{|c|}{ MV in cases without dementia } & \multirow[t]{2}{*}{ Parallelism tes } \\
\hline & 2000 & 2013 & AAPC $(95 \%$ Cl) & 2000 & 2013 & AAPC $(95 \% \mathrm{Cl})$ & \\
\hline Proportion (\%) & 1.51 & 2.64 & $3.8(3.0,4.5)^{\dagger}$ & 98.5 & 97.4 & $-0.1(-0.1,-0.1)^{\dagger}$ & $P<0.001$ \\
\hline Hospital discharge rate (per 10,000 ) & 1.76 & 3.57 & $4.71(3.6,5.8)^{\dagger}$ & 114 & 131 & $0.91(0.4,1.4)^{\dagger}$ & $P=0.005$ \\
\hline Population rate (per 100,000) & 3.1 & 6.9 & $5.39(4.0,6.7)^{\dagger}$ & 203.6 & 253.3 & $1.62(0.9,2.4)^{\dagger}$ & $P=0.030$ \\
\hline$M V \geq 96 \mathrm{~h}(\%)$ & 24.6 & 28.4 & $-0.8(-2.3,0.7)$ & 31.2 & 34.9 & $0.99(0.7,1.3)^{\dagger}$ & $P=0.031$ \\
\hline CFR (\%) & 55.9 & 50.2 & $-0.30(-1.1,0.5)$ & 51.9 & 44.5 & $-1.19(-1.3,-1.0)^{\dagger}$ & $P=0.10$ \\
\hline
\end{tabular}

$M V$ invasive mechanical ventilation, $A A P C$ average annual percentage change, $95 \% \mathrm{Cl} 95 \%$ confidence interval, CFR: case fatality rate

${ }^{\dagger}$ Statistically significant 


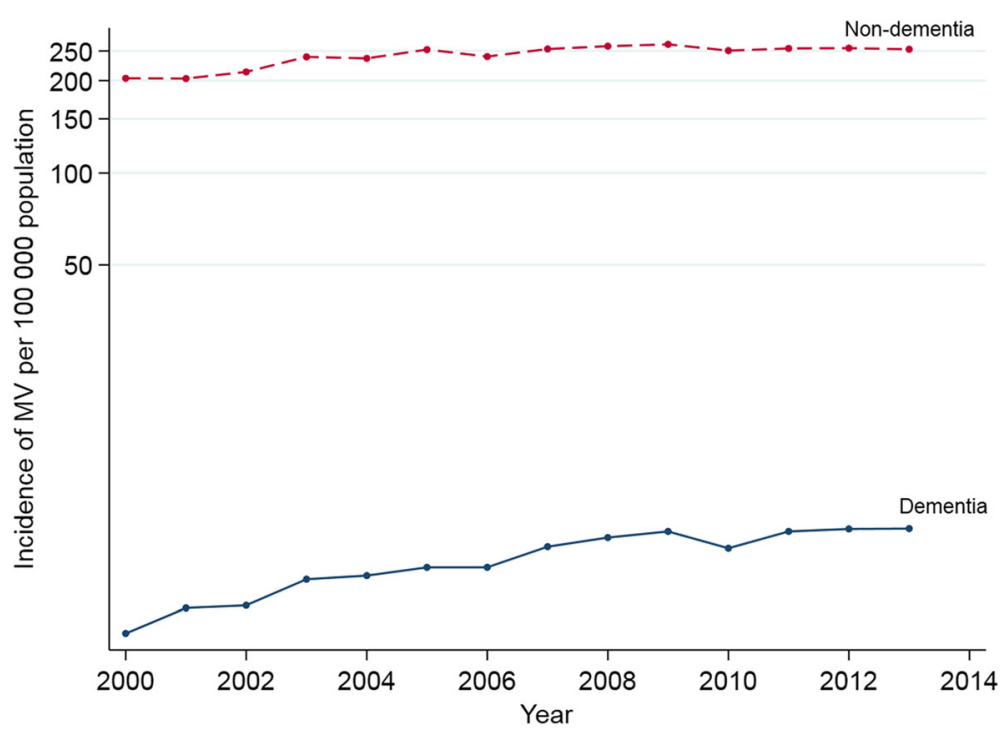

Fig. 1 Trends in invasive mechanical ventilation incidence rates in patients with and without dementia. The figure shows the changes observed over time in incidence rates. The cohort with dementia reaches a greater increase than the cohort without dementia

Our dementia group showed an older age and higher percentage of women, as described by others [16]. However, our cases had a lower comorbidity burden which could be partly due to the different score system used as there is still no standardized method to assess this issue despite its important role in patient's outcomes [33]. For this study, we selected the Charlson comorbidity index as it has shown a similar capacity to scales based on physiological scores to predict mortality in critically ill patients [34].
As expected, in-hospital mortality was really high in both cohorts. But, a main finding of our study was the lack of significant differences in CFR between both cohorts once adjusted for remaining clinical-demographic variables, meaning that dementia has not had a significant impact on hospital mortality in individuals $\geq 65$ years subjected to MV. This finding, which is in line with the data reported by Lagu et al. [16], also suggests the use of MV in persons with dementia in our country complies (at least in terms of mortality as an effect

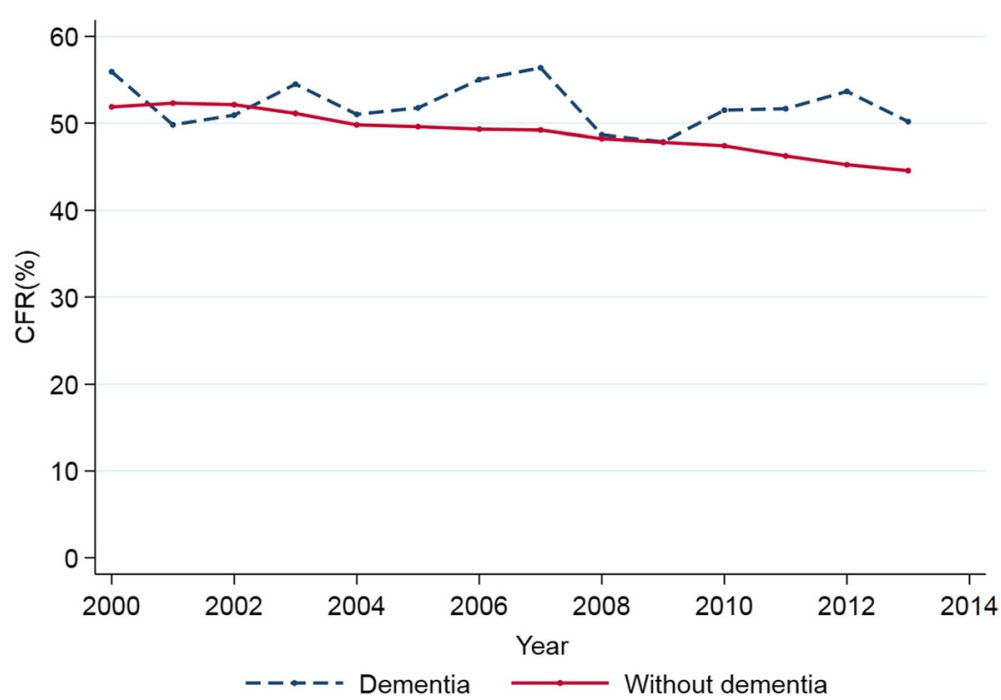

Fig. 2 Trends in in-hospital mortality in MV episodes of patients with and without dementia. The figure shows the changes observed over time in in-hospital mortality. Note that cases with dementia do not show the downward trend detected in the cases without dementia; rather, they feature a fluctuating trend over the period of study 

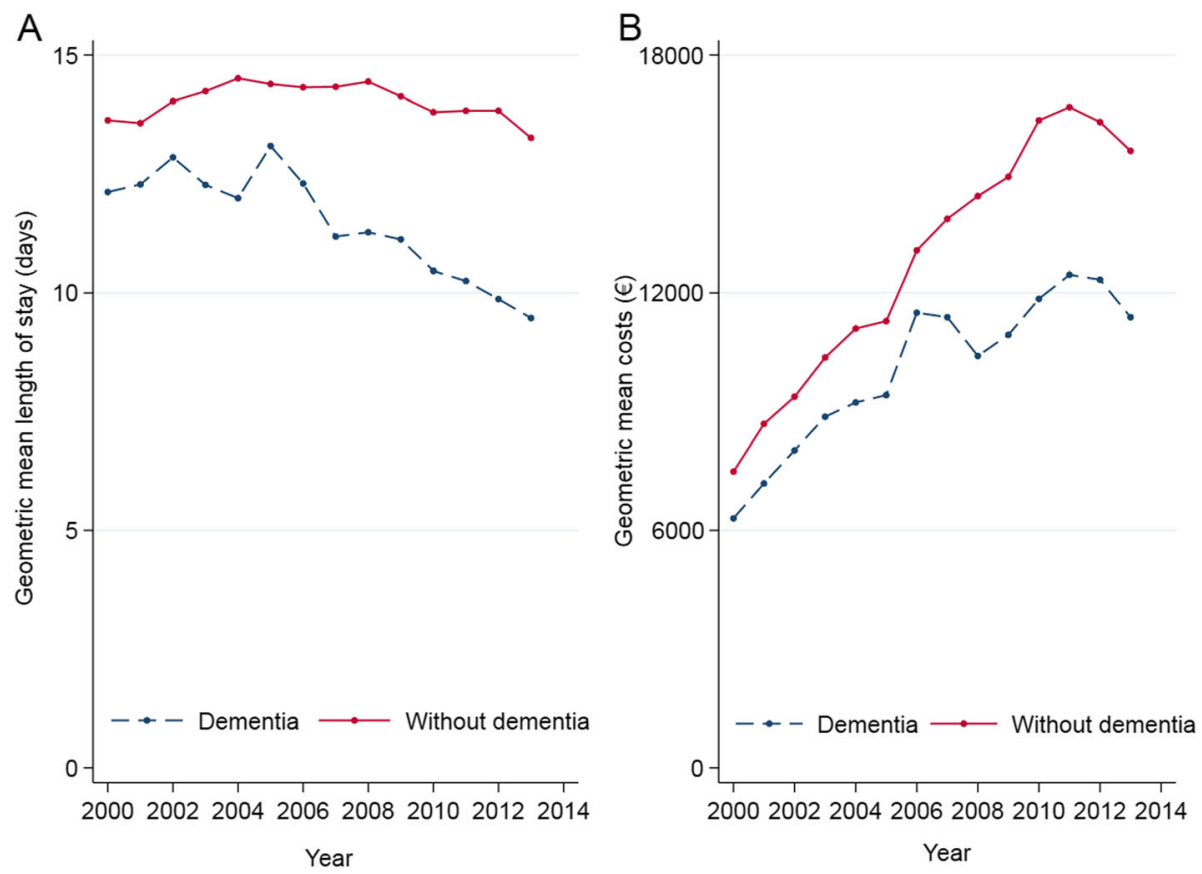

Fig. 3 Trends in hospital resources in patients with and without dementia. a Over the period examined, geometric mean hospital stay has decreased significantly in cases with dementia passing from 12.12 days in the year 2000 to 9.47 days in 2013. In contrast, in cases without dementia, mean stay has remained stable passing from 13.63 to 13.26. b Over the period examined, geometric mean costs per case in the group with dementia have risen significantly from 6305€ in 2000 to 11,384€ in 2013 and in cases without dementia from 7485€ to 15,583€ (both $p<0.001$ )

measure) with the quality standard of its use in patients $\geq 65$ years without dementia.

Our trends analysis, nevertheless, indicates that while hospital mortality in the dementia-free cohort has steadily declined over the 14 years examined, which is consistent with literature reports [35], we observed no parallel changes in the dementia cohort.

Something similar can be said about the trend observed in the use of hospital resources. While some studies have shown that dementia leads to longer mean hospital stay and costs in older patients admitted because of acute illness $[3,4]$, our finding is consistent with more recent descriptions [16, 36] that these variables are significantly lower in patients with dementia. Our study also reveals that this reduced resource use in patients with dementia persists when the extent of MV was introduced as a covariate in the adjusted multivariate model. Additionally, trend analysis indicate that mean length of stay difference has increased over the years since while the mean hospital stay in cases without dementia has remained stable, it has progressively decreased in cases with dementia.

Unfortunately, the database design prevents any causal inferences or assessment of other reasons that could justify these trends, such as the existence of advanced directives, family preferences, or clinical practices toward the limitation of therapeutic efforts and the use, instead, of comfort measures. We consider those data are fundamental and that it is necessary to study them in a prospective way.

Our observations extend the scarce available information on the incidence and short-term outcomes of the use of invasive technologies such as MV in adults aged $\geq 65$ years with dementia, and perhaps, they can be of help in the existing debate about the use of these therapeutic measures in patients with dementia. Further, given the national population-based nature of our data, we feel they may be generalizable and of interest for clinical decision making and healthcare resource planning in an increasingly aging society for which a greater prevalence of dementia is foreseen in the near future $[15,37,38]$.

\section{Limitations}

Our study has several limitations we should mention. When working with clinical-administrative data, sensitivity to detect the variables of interest depends directly on the discharge report completed by the responsible physician. There is evidence to suggest that dementia has been undercoded in discharge reports, especially in mild or complex cases [39]. To minimize this limitation, we used a broad definition of dementia in line with previous, similar studies $[14,16]$, even though these definitions have not been validated against clinical charts. 
Moreover, MV is a major procedure which is easily identified in a patient's clinical record and whose ICD-9-CM codes are stable and validated [20]. However, we did not have access to staging information of our dementia cases. Given that an inverse relationship has been established between dementia severity and the frequency at which patients are hospitalized and that some clinical guidelines emphasize the need to treat persons with dementia at their homes [37], it is likely that our dementia cohort will contain a high proportion of mild-moderate severity cases. Our data source also prevents us from knowing other individual factors such as pharmacological treatments; the existence of an advance directive or their socio-cultural or educational level which makes it impossible to further characterize this cohort and stratify the results according to these factors. Nonetheless, given the universal character of our national health system with equal access to the whole population, aspects such as the socioeconomic level have not influenced the results obtained. Likewise, given the regulation of our national health system, we can assume that clinical and coding practices have not been related to economic incentives. Also, our database does not include physiology-based scores of common use in ICUs, such as APACHE or SAPS. Notwithstanding, Christensen and colleagues have shown that the Charlson comorbidity index performs similarly to physiology-based scores at predicting short- and long-term mortality for ICU patients [34]. Finally, because of this study's retrospective nature, we cannot rule out that temporal trends may, at least in part, be associated with different treatment practices during the long period of study. However, the population nature of our study, its main strength, means we can assume a lack of selection bias and can also extrapolate its results. In addition, RECORD recommendations for reporting of results were followed [40].

\section{Conclusions}

This nationwide population-based study reveals no impact of dementia on in-hospital mortality in elderly patients undergoing invasive mechanical ventilation. However, dementia is significantly associated with shorter stay and hospital costs. Our data also identifies a recent marked increase in the use of this lifesupport measure in elderly patients with dementia and that this increase is much greater than that observed in elderly individuals without dementia. This data have important implications for clinical decisionmaking and healthcare resource planning in an increasingly aging society for which a greater prevalence of dementia is foreseen in the near future.

\section{Additional file}

Additional file 1: Table S1. General characteristics and outcomes of cases by duration of invasive mechanical ventilation (MV). (DOCX $16 \mathrm{~kb}$ )

\section{Acknowledgements \\ We would especially like to thank the Subdirección General de Información Sanitaria e Innovación (Ministry of Health, Social Services and Equality) for providing the data used in this study.}

\section{Authors' contributions \\ All authors meet the International Committee of Medical Editors criteria for authorship. CB designed the study; participated in the acquisition, analysis, and interpretation of the data; drafted and revised the manuscript; and obtained funding. GMA participated in the statistical analysis, made substantial contributions to the interpretation of the data, and drafted and revised the manuscript. TLC participated in the acquisition and data curation, performed the statistical analysis and revised the manuscript. All authors read and approved the final manuscript.}

\section{Funding}

This research was supported by the Instituto de Salud Carlos III (grant number PI14/00081). The funding source has no role in the design and conduct of the study, the analysis and interpretation of data, or in the writing of the manuscript.

\section{Availability of data and materials}

The data are anonymized and, according to Spanish law, are exempt from the necessity for informed consent. They come from hospital discharge records collected and de-identified by the Spanish Ministry of Health, Social Services and Equality. The authors requested and obtained access to the data from the Ministry and, due to a signed confidential agreement, cannot share these data with third parties. However, these records are publicly available for research purposes. Requests of access to the data should be addressed directly to the Ministry.

\section{Ethics approval and consent to participate}

Not applicable

\section{Consent for publication}

All authors have reviewed the manuscript and approved the publication.

\section{Competing interests}

The authors declare that they have no competing interests.

\section{Author details}

${ }^{1}$ Health Technology Assessment Agency, Carlos III Health Institute, c/ Monforte de Lemos 5, Pab 4, 28029 Madrid, Spain. ${ }^{2}$ Department of Epidemiology, Columbia University Mailman School of Public Health, New York, NY, USA. ${ }^{3}$ School of Medicine, Autonomous University of Madrid, Madrid, Spain. ${ }^{4}$ National Centre of Epidemiology, Carlos III Health Institute, Madrid, Spain.

Received: 20 May 2019 Accepted: 21 August 2019

Published online: 30 August 2019

\section{References}

1. Prince M, Bryce R, Albanese E, Wimo A, Ribeiro W, Ferri CP. The global prevalence of dementia: a systematic review and metaanalysis. Alzheimers Dement. 2013;9:63-75.

2. Wimo A, Guerchet M, Ali G-C, Wu YT, Prina AM, Winblad B, Jönsson L, Liu Z, Prince M. The worldwide costs of dementia 2015 and comparisons with 2010. Alzheimers Dement. 2017;13(1):1-7. https://doi. org/10.1016/j.jalz.2016.07.150.

3. Bynum JP, Rabins PV, Weller W, Niefeld M, Anderson GF, Wu AW. The relationship between a dementia diagnosis, chronic illness, medicare expenditures, and hospital use. J Am Geriatr Soc. 2004;52(2):187-94.

4. Lyketsos CG, Sheppard JM, Rabins PV. Dementia in elderly persons in a general hospital. Am J Psychiatry. 2000;157(5):704-7. https://doi.org/10.1176/ appi.ajp.157.5.704. 
5. Sampson EL, Blanchard MR, Jones L, Tookman A, King M. Dementia in the acute hospital: prospective cohort study of prevalence and mortality. $\mathrm{Br} J$ Psychiatry. 2009;195(1):61-6. https://doi.org/10.1192/bjp.bp.108.055335.

6. Pisani MA, Redlich CA, McNicoll L, Ely EW, Friedkin RJ, Inouye SK. Short-term outcomes in older intensive care unit patients with dementia. Crit Care Med. 2005;33(6):1371-6.

7. Milbrandt EB. Dementia: a justification for limiting intensive care? Crit Care Med. 2005;33:1457-8. https://doi.org/10.1097/01.CCM.0000166705.61231.B5.

8. Richardson SS, Sullivan G, Hill A, Yu W. Use of aggressive medical treatments near the end of life: differences between patients with and without dementia. Health Serv Res. 2007;42(1 Pt 1):183-200. https://doi. org/10.1111/j.1475-6773.2006.00608.x.

9. Oud L. Intensive care unit (ICU) - managed elderly hospitalizations with dementia in Texas, 2001-2010: a population-level analysis. Med Sci Monit. 2016:22:3849-59.

10. Wunsch $H$, Linde-Zwirble WT, Angus DC, Hartman ME, Milbrandt EB, Kahn JM. The epidemiology of mechanical ventilation use in the United States. Crit Care Med. 2010;38:1947-53.

11. Barnato AE, Albert SM, Angus DC, Lave JR, Degenholtz HB. Disability among elderly survivors of mechanical ventilation. Am J Respir Crit Care Med. 2011; 183:1037-42.

12. Jackson JC, Pandharipande PP, Girard TD, Brummel NE, Thompson JL, Hughes CG, Pun BT, Vasilevskis EE, Morandi A, Shintani AK, Hopkins RO, Bernard GR, Dittus RS, Ely EW. Bringing to light the Risk Factors And Incidence of Neuropsychological dysfunction in ICU survivors (BRAIN-ICU) study investigators. Depression, post-traumatic stress disorder, and functional disability in survivors of critical illness in the BRAIN-ICU study: a longitudinal cohort study. Lancet Respir Med. 2014;2(5):369-79. https://doi. org/10.1016/S2213-2600(14)70051-7

13. Dasta JF, McLaughlin TP, Mody SH, Piech CT. Daily cost of an intensive care unit day: the contribution of mechanical ventilation. Crit Care Med. 2005;33:1266-71.

14. Lagu T, Zilberberg MD, Tjia J, Pekow PS, Lindenauer PK. Use of mechanical ventilation by patients with and without dementia, 2001 through 2011. JAMA Intern Med. 2014;174(6):999-1001. https://doi.org/10.1001/ jamainternmed.2014.1179.

15. Borjaille CZ, Hill AD, Pinto R, Fowler RA, Scales DC, Wunsch H. Rates of mechanical ventilation for patients with dementia in Ontario: a populationbased cohort study. Anesth Analg. 2019. https://doi.org/10.1213/ANE. 0000000000004003.

16. Lagu T, Zilberberg MD, Tjia J, Shieh MS, Stefan M, Pekow PS, Lindenauer PK. Dementia and outcomes of mechanical ventilation. J Am Geriatr Soc. 2016; 64(10):e63-e6. https://doi.org/10.1111/jgs.14344.

17. Ministerio de Sanidad, Consumo y Bienestar Social. Actividad y Calidad de los Servicios Sanitarios. Informe anual del Sistema Nacional de Salud, 2017. Available from: https://www.mscbs.gob.es/estadEstudios/ estadisticas/sisInfSanSNS/tablasEstadisticas/InfAnualSNS2017/5_CAP_17. pdf. Accessed 12 Feb 2019.

18. Instituto Nacional de Estadística. http://www.ine.es/ Accessed 24 Sept 2018.

19. Agencia Estatal Boletín Oficial del Estado. Law14/2007, of 3 July, on Biomedical Research. http://www.boe.es/boe/dias/2007/07/04/. Accessed 24 Sept 2018

20. Kerlin MP, Weissman GE, Wonneberger KA, Kent S, Madden V, Liu VX, Halpern SD. Validation of administrative definitions of invasive mechanical ventilation across 30 intensive care units. Am J Respir Crit Care Med. 2016; 194(12):1548-52. https://doi.org/10.1164/rccm.201605-0953LE.

21. Gale SA, Acar D, Daffner KR. Dementia. Am J Med. 2018;131(10):1161-9.

22. Deyo RA, Cherkin DC, Ciol MA. Adapting a clinical comorbidity index for use with ICD-9-CM administrative databases. J Clin Epidemiol. 1992;45(6):613-9.

23. Quan H, Sundararajan V, Halfon P, Fong A, Burnand B, Luthi JC, Saunders $L D$, Beck CA, Feasby TE, Ghali WA. Coding algorithms for defining comorbidities in ICD-9-CM and ICD-10 administrative data. Med Care. 2005; 43(11):1130-9.

24. Shen HN, Lu CL, Li CY. Dementia increases the risks of acute organ dysfunction, severe sepsis and mortality in hospitalized older patients: a national population-based study. PLoS One. 2012;7(8):e42751. https://doi. org/10.1371/journal.pone.0042751.

25. Librero J, Peiró S, Ordiñana R. Chronic comorbidity and outcomes of hospital care: length of stay, mortality and readmission at 30 and 365 days. J Clin Epidemiol. 1999:52:171-9.
26. Kim HJ, Fay MP, Feuer EJ, Midthune DN. Permutation tests for joinpoint regression with applications to cancer rates. Stat Med. 2000:19:335-51.

27. Clegg LX, Hankey BF, Tiwari R, Feuer EJ, Edwards BK. Estimating average annual percent change in trend analysis. Stat Med. 2000;28:3670-8.

28. Wunsch H, Angus DC, Harrison DA, Collange O, Fowler R, Hoste EA, de Keizer NF, Kersten A, Linde-Zwirble WT, Sandiumenge A, Rowan KM. Variation in critical care services across North America and Western Europe. Crit Care Med. 2008;36(10):2787-93. e1-9. https://doi.org/10.1097/CCM.0b013 e318186aec8.

29. Teno JM, Gozalo P, Khandelwal N, Curtis JR, Meltzer D, Engelberg R, Mor V. Association of increasing use of mechanical ventilation among nursing home residents with advanced dementia and intensive care unit beds. JAMA Intern Med. 2016;176(12):1809-16. https://doi.org/10.1001/ jamainternmed.2016.5964.

30. Rhodes A, Ferdinande P, Flaatten H, Guidet B, Metnitz PG, Moreno RP. The variability of critical care bed numbers in Europe. Intensive Care Med. 2012; 38:1647-53

31. Martín MC, León C, Cuñat F, del Nogal F. Recursos estructurales de los Servicios de Medicina Intensiva en España. Med Int. 2013;37(7):443-51.

32. Wallace DJ, Angus DC, Seymour CW, Barnato AE, Kahn JM. Critical care bed growth in the United States. A comparison of regional and national trends. Am J Respir Crit Care Med. 2015;191(4):410-6. https://doi.org/10.1164/rccm.2 01409-17460C.

33. Hall SF. A user's guide to selecting a comorbidity index for clinical research. J Clin Epidemiol. 2006;59:849-55.

34. Christensen $S$, Johansen MB, Christiansen $C F$, Jensen $R$, Lemeshow $S$. Comparison of Charlson comorbidity index with SAPS and APACHE scores for prediction of mortality following intensive care. Clin Epidemiol. 2011;3: 203-11. https://doi.org/10.2147/CLEP.S20247.

35. Esteban A, Frutos-Vivar F, Muriel A, Ferguson ND, Peñuelas O, Abraira $V$, Raymondos K, Rios F, Nin N, Apezteguía C, Violi DA, Thille AW, Brochard L, González M, Villagomez AJ, Hurtado J, Davies AR, Du B, Maggiore SM, Pelosi P, Soto L, Tomicic V, D'Empaire G, Matamis D, Abroug F, Moreno RP, Soares MA, Arabi Y, Sandi F, Jibaja M, Amin P, Koh Y, Kuiper MA, Bülow HH, Zeggwagh AA, Anzueto A. Evolution of mortality over time in patients receiving mechanical ventilation. Am J Respir Crit Care Med. 2013:188(2):220-30.

36. Bouza C, Martínez-Alés G, López-Cuadrado T. The impact of dementia on hospital outcomes for elderly patients with sepsis: a population-based study. PLoS One. 2019;14(2):e0212196. https://doi.org/10.1371/journal.pone. 0212196.

37. Prince M, Ali GC, Guerchet M, Prina AM, Albanese E, Wu YT. Recent global trends in the prevalence and incidence of dementia, and survival with dementia. Alzheimers Res Ther. 2016;8(1):23. https://doi.org/10.1186/s13195016-0188-8

38. Shah H, Albanese E, Duggan C, Rudan I, Langa KM, Carrillo MC, Chan KY, Joanette $Y$, Prince M, Rossor M, Saxena S, Snyder HM, Sperling R, Varghese M, Wang H, Wortmann M, Dua T. Research priorities to reduce the global burden of dementia by 2025. Lancet Neurol. 2016;15(12):1285-94. https:// doi.org/10.1016/S1474-4422(16)30235-6.

39. National Institute for Clinical Excelence (NICE) Guideline 97. 2018. https:// www.nice.org.uk/guidance/ng97. Accessed 2 Aug 2018.

40. Benchimol El, Smeeth L, Guttmann A, Harron K, Moher D, Petersen I, Sørensen HT, von Elm E, Langan SM. RECORD Working Committee. The REporting of studies Conducted using Observational Routinely-collected health Data (RECORD) statement. PLoS Med. 2015;12(10):e1001885. https:// doi.org/10.1371/journal.pmed.1001885.

\section{Publisher's Note}

Springer Nature remains neutral with regard to jurisdictional claims in published maps and institutional affiliations. 